\title{
KEEFEKTIFAN MODEL COOPERATIVE INTEGRATED READING AND COMPOSITION TERHADAP HASIL BELAJAR MEMBACA INTENSIF SISWA KELAS III SD
}

\author{
Erly Mardhiana \\ PGSD, FIP Universitas PGRI Semarang \\ E-mail: mardhianaerly@gmail.com
}

\begin{abstract}
This research is motivated by the low learning result of intensive reading of students which one of them is caused by less active, creative, and innovative learning process. This study aims to determine the effectiveness of the CIRC model of intensive reading learning outcomes of third grade students of SDN Bogorame Rembang. This research is a quantitative research with Pre-Experimental design with One Group Pretest-Posstest type. The sample technique used is nonprobability sampling with saturated sampling type. Population in this research is all student class III SDN Bogorame Rembang academic year 2017/2018. The result of the research shows that CIRC model is effective toward students' intensive reading learning as evidenced by $\mathrm{t}$-test with $\mathrm{t}_{\text {count }}=4,4986>\mathrm{t}_{\text {table }}=2,1448$.
\end{abstract}

Keywords: CIRC, The Results of Learning Intensive Reading

\begin{abstract}
Abstrak
Penelitian ini dilatarbelakangi karena rendahnya hasil belajar membaca intensif siswa yang salah satunya diakibatkan oleh proses pembelajaran yang kurang aktif, kreatif, dan inovatif. Penelitian ini bertujuan untuk mengetahui keefektifan model CIRC terhadap hasil belajar membaca intensif siswa kelas III SDN Bogorame Rembang. Penelitian ini adalah penelitian kuantitatif dengan desain Pre-Experimental dengan jenis One Group PretestPosstest. Teknik sampel yang digunakan adalah nonprobability sampling dengan jenis sampling jenuh. Populasi dalam penelitian ini adalah seluruh siswa kelas III SDN Bogorame Rembang tahun ajaran 2017/2018. Hasil dari penelitian menunjukkan bahwa model CIRC efektif terhadap hasil belajar membaca intensif siswa yang dibuktikan dengan uji $t$-test dengan perolehan $\mathrm{t}_{\text {hitung }}=4,4986>\mathrm{t}_{\text {tabel }}=2,1448$.

Kata kunci : CIRC, Hasil Belajar Membaca Intensif
\end{abstract}

\section{PENDAHULUAN}

Dalam pendidikan, pembelajaran yang berkualitas adalah hal yang sangat diperlukan demi kemajuan pendidikan itu sendiri. Pendidikan yang berkualitas salah satunya dapat didukung dengan pembelajaran yang aktif, kreatif, dan inovatif agar dapat mendorong untuk meningkatkan hasil belajar siswa. UndangUndang Nomor 20 Tahun 2003 tentang Sistem Pendidikan Nasional, Pasal 1 ayat 1 menyatakan bahwa pendidikan adalah usaha sadar dan terencana untuk mewujudkan suasana belajar dan proses pembelajaran agar peserta didik secara aktif mengembangkan potensi dirinya untuk memiliki kekuatan spiritual keagamaan, pengendalian diri, kepribadian, kecerdasan, akhlak mulia, serta keterampilan yang diperlukan dirinya, masyarakat, bangsa dan negara.

Pada kenyataannya masih terdapat berbagai masalah yang harus diselesaikan demi pelaksanaan pembalajaran yang berkualitas dalam dunia pendidikan terkait dengan pembelajaran yang aktif, kreatif, dan inovatif. Sesuai dengan Peraturan Menteri Pemerintahan Republik Indonesia Nomor 22 Tahun 2006 Tentang Standar Proses Pendidikan Dasar dan Menengah menyatakan bahwa Proses Pembelajaran 
pada satuan pendidikan diselenggarakan secara interaktif, inspiratif, menyenangkan, menantang, memotivasi peserta didik untuk berpartisipasi aktif, serta memberikan ruang yang cukup bagi prakarsa, kreativitas, dan kemandirian sesuai dengan bakat, minat, dan perkembangan fisik serta psikologis peserta didik. Untuk itu setiap satuan pendidikan melakukan perencanaan pembelajaran, pelaksanaan proses pembelajaran serta penilaian proses pembelajaran untuk meningkatkan efisiensi dan efektivitas ketercapaian kompetensi lulusan. Dari pernyataan tersebut dijelaskan bahwa salah satu proses pembelajaran adalah menyenangkan. Dalam hal ini salah satu upaya yang dapat dilakukan guru untuk membuat suasana belajar bisa menjadi menyenangkan adalah dengan menggunakan model, metode, media, dan strategi yang inovatif dan sesuai.

Peraturan Menteri Pemerintahan Republik Indonesia Nomor 103 Tahun 2014 Pasal 2 juga menyatakan bahwa pembelajaran dilaksanakan berbasis aktivitas dengan karakteristik; (1) interaktif dan inspiratif (2) menyenangkan, menantang, dan memotivasi peserta didik untuk berpartisipasi aktif (3) kontekstual dan kolaboratif (4) memberikan ruang yang cukup bagi prakarsa, kreativitas, dan kemandirian peserta didik, dan (5) sesuai dengan bakat, minat, kemampuan, dan perkembangan fisik serta psikologis peserta didik. Kenyataan di lapangan, guru hanya menggunakan metode ceramah saat pembelajaran. Hal ini akan membuat kesan yang membosankan bagi siswa. Maka dari itu guru dapat menggunakan model, metode, media, maupun strategi pembelajaran yang bervariasi.

Masalah lain yang muncul yaitu mengenai hasil belajar siswa. Dimana seharusnya hasil belajar siswa bisa maksimal sesuai dengan target guru. Sedangkan saat ini masih didapati dalam beberapa mata pelajaran bahwa hasil belajar siswa masih rendah. Menurut Rusman (2017: 131) terdapat dua faktor yang mempengaruhi hasil belajar, yaitu faktor internal dan eksternal. Faktor internal terdiri dari faktor fisik dan psikologi. Sedangkan faktor eksternal terdiri dari faktor lingkungan dan instrumental seperti kurikulum, sarana, dan guru.

Berdasarkan hasil observasi di SDN Bogorame Rembang pada pembelajaran bahasa Indonesia didapati bahwa dari 21 siswa kelas III, terdapat 11 siswa yang belum tuntas KKM. Berdasarkan data tersebut dimungkinkan: (1) hasil belajar membaca intensif siswa rendah karena guru masih menggunakan metode ceramah, tanya jawab, dan penugasan (2) hasil belajar membaca intensif siswa rendah karena guru belum menggunakan model pembelajaran yang kooperatif (3) hasil belajar membaca intensif siswa rendah karena guru tidak menggunakan media sama sekali (4) hasil belajar membaca intensif siswa rendah karena hanya beberapa siswa yang aktif tanya jawab dengan guru. Padahal sebagai seorang guru profesional harus kreatif dan inovatif dalam mengelola kelas.

Dari berbagai masalah tersebut, peneliti akan memberikan solusi berupa pemberian perlakuan dengan menggunakan salah satu model pembelajaran kooperatif yang mampu meningkatkan kemampuan membaca intensif siswa kelas III SDN Bogorame yaitu model Cooperative Integrated Reading and Composition. Model pembelajaran CIRC bisa dikatakan efektif karena melihat dari kecocokan model pembelajaran tersebut dengan materi pembelajaran itu sendiri. Sesuai pendapat Rahim (2008: 35) mengatakan bahwa pembelajaran kooperatif yang lebih cocok dengan pembelajaran membaca adalah menggunakan model CIRC. Hal tersebut didorong oleh pendapat Ratumanan (2015: 150) mengatakan bahwa pembelajaran kooperatif menekankan bahwa manusia adalah makhluk sosial. Sebagai makhluk sosial, kerjasama merupakan aspek yang penting dalam mencapai tujuan. Dalam pembelajaran, kerjasama akan lebih memudahkan peserta didik untuk mencapai suatu tujuan pembelajaran. 
Penelitian terhadap model CIRC pernah dilakukan oleh Utami, dkk dengan judul penelitian yaitu Pengaruh Model Cooperative Integrated Reading and Composition terhadap Hasil Belajar IPA Siswa Kelas $V$. Peneliti menyimpulkan bahwa terdapat perbedaan yang signifikan hasil belajar IPA antara siswa yang mengikuti model Pembelajaran CIRC dengan siswa yang mengikuti pembelajaran konvensional pada siswa kelas V di SD 4 Tuban tahun pelajaran 2013/2014. Karena

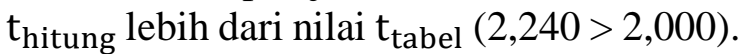
Rata-rata hasil belajar kelas eksperimen lebih besar dari hasil belajar kelas kontrol oleh karena itu dari hasil tersebut penerepan model CIRC berpengaruh terhadap hasil belajar IPA siswa kelas V di SD Tuban Tahun pelajaran 2013/2014.

Dari uraian masalah di atas, peneliti tertarik untuk melakukan penelitian yang berjudul Keefektifan Model Cooperative Integrated Reading and Composition terhadap Hasil Belajar Membaca Intensif Siswa Kelas III SDN Bogorame Rembang. Adapun tujuan dari penelitian ini adalah untuk mengetahui keefektifan model Cooperative Integrated Reading and Composition terhadap Hasil Belajar Membaca Intensif Siswa Kelas III SDN Bogorame Rembang.

\section{METODE}

Penelitian ini adalah penelitian kuantitatif dengan desain Pre-Experimental dengan jenis One Group Pretest-Posstest. Teknik sampling yang digunakan dalam penelitian ini adalah teknik sampling jenuh dengan populasi dalam penelitian ini adalah seluruh siswa kelas III SDN Bogorame Rembang. Data diperoleh dari hasil test pretest dan posttest. Teknik pengumpulan data yang digunakan adalah observasi, dokumentasi, dan tes. Analisis data dalam penelitian ini adalah uji normalitas (Liliefors) dan uji $t$ test.

\section{KAJIAN PUSTAKA}

Dalam penelitian ini kajian teori yang akan dibahas yaitu hasil belajar membaca intensif dan CIRC. Menurut Suprijono (2017: 5), hasil belajar yaitu pola perbuatan, nilai, pengertian, sikap, apresiasi, dan ketrampilan. Menurut Dalman (2017: 87), membaca intensif adalah ketrampilan membaca yang lebih tinggi. Membaca intensif merupakan membaca secara kognitif yaitu membaca untuk memahami. Dalam membaca intensif, pembaca dituntut untuk dapat memahami isi bacaan. Maka dari itu setelah membaca sebuah teks, pembaca hendaknya dapat mengungkapkan dengan bahasa sendiri isi bacaan yang dibaca baik secara lisan maupun tulisan. Kemudian CIRC menurut Huda (2013: 126) adalah suatu model pembelajaran yang dikembangkan dan dirancang untuk mengakomodasi level kemampuan siswa yang beragam baik dalam pengelompokan heterogen maupun homogen. Dalam pembelajaran $C I R C$, siswa dikelompokkan ke dalam kelompok-kelompok kecil baik homogen maupun heterogen.

\section{HASIL}

Hasil dari penelitian yaitu model CIRC efektif terhadap hasil belajar membaca intensif siswa kelas III SDN Bogorame Rembang. Sesuai dengan kriteria efektif yaitu pretes < postes $\geq \operatorname{KKM}(57,33<$ $70,22 \geq 64)$. Hal tersebut juga diperkuat dari hasil uji normalitas awal diperoleh hasil $\mathrm{L}_{0}$ 0,1652 dengan taraf nyata $5 \%(0,05)$ dan $\mathrm{L}_{\text {tabel }} 0,2289$. Berdasarkan kriteria $\mathrm{L}_{0} \leq \mathrm{L}_{\text {tabel }}$ diperoleh $0,1652 \leq 0,2289$. Maka, $\mathrm{H}_{0}$ diterima sehingga dapat disimpulkan sampel berasal dari distribusi normal. Sedangkan uji normalitas akhir diperoleh $\mathrm{L}_{0} 0,1271$ dengan taraf nyata $5 \%(0,05)$ dan $\mathrm{L}_{\text {tabel }} 0,2289$. Berdasarkan kriteria $\mathrm{L}_{0} \leq \mathrm{L}_{\text {tabel }}$ diperoleh $0,1271 \leq 0,2289$. Maka, $\mathrm{H}_{0}$ diterima sehingga dapat disimpulkan sampel berasal dari distribusi normal.

Selain itu berdasarkan hasil uji t-test diperoleh $t_{\text {hitung }}$ sebesar 4.49862 dan $t_{\text {tabel }}$ diperoleh dari $\mathrm{db}=(\mathrm{N}-1)=15-1=14$ taraf signifikan 5\% $(0,05)$ sebesar 2.14479. Jadi $\mathrm{t}_{\text {hitung }} 4.49862 \geq \mathrm{t}_{\text {tabel }} 2.14479$. Karena $\mathrm{t}_{\text {hitung }}$ $\geq t_{\text {tabel, }}$ maka $\mathrm{H}_{0}$ ditolak. Artinya rataan hasil belajar membaca intensif siswa 
sebelum dan sesudah perlakuan tidak sama/meningkat.

\section{PEMBAHASAN}

Penelitian ini dilaksanakan di kelas III SDN Bogorame Rembang tahun pelajaran 2017. Teknik samping yang digunakan dalam penelitian ini adalah nonprobability sampling dengan jenis sampling jenuh. Sampel dalam penelitian ini adalah kelas III SDN Bogorame Rembang dengan jumlah siswa 15.

Dari hasil penelitian ditemukan masalah hasil belajar membaca intensif siswa kelas III SDN Bogorame Rembang masih di bawah KKM. Oleh karena itu setelah melakukan observasi maka peneliti memberikan solusi permasalahan berupa penerapan model pembelajaran CIRC. Pemilihan model CIRC ini karena sesuai dengan pendapat Rahim (2008: 35) mengatakan bahwa pembelajaran kooperative yang lebih cocok dengan pembelajaran membaca adalah menggunakan model $C I R C$. Lalu menurut Ratumanan (2015: 150) mengatakan bahwa sebagai makhluk sosial, kerjasama merupakan aspek yang penting dalam mencapai tujuan. Dalam pembelajaran, kerjasama akan lebih memudahkan peserta didik untuk mencapai suatu tujuan pembelajaran.

Dalam pembelajaran CIRC siswa dilatih untuk saling bekerjasama menyampaikan pendapat untuk menemukan isi dari teks bacaan yang diberikan. Dengan diskusi yang baik diharapkan agar siswa mampu mengingat apa saja yang sudah didiskusikan juga agar siswa yang malu bertanya kepada guru bisa mendapatkan pelajaran baru dari teman sebaya dalam kelompok disukusinya. Lalu dengan adanya diskusi dalam model CIRC juga diharapkan agar siswa mampu menyelesaikan masalah lebih mudah.

Untuk mengetahui keefektifan model CIRC terhadap hasil belajar siswa, peneliti melakukan teknik tes berupa pretes dan postes. Soal pretes diberikan kepada siswa sebelum diberikan perlakuan, sedangkan soal postes diberikan kepada siswa setelah diberi perlakuan. Jumlah soal adalah 10 butir soal dalam bentuk uraian. Sebelumnya butir soal di validasi dengan dosen ahli untuk syarat kelayakan.

Setelah mendapatkan hasil pretes dan postes selanjutnya dilakukan uji normalitas awal dan akhir untuk mengetahui data berdistribusi normal atau tidak. Berdasarkan perhitungan uji normalitas awal diperoleh hasil $\mathrm{L}_{0} 0,1652$ dengan taraf nyata $5 \% \quad(0,05)$ dan $\mathrm{L}_{\text {tabel }} 0,2289$. Berdasarkan kriteria $\mathrm{L}_{0} \leq \mathrm{L}_{\text {tabel }}$ diperoleh $0,1652 \leq 0,2289$. Maka, $\mathrm{H}_{0}$ diterima sehingga dapat disimpulkan sampel berasal dari distribusi normal. Sedangkan uji normalitas akhir diperoleh $\mathrm{L}_{0} 0,1271$ dengan taraf nyata $5 \%(0,05)$ dan $\mathrm{L}_{\text {tabel }} 0,2289$. Berdasarkan kriteria $\mathrm{L}_{0} \leq \mathrm{L}_{\text {tabel }}$ diperoleh $0,1271 \leq 0,2289$. Maka, $\mathrm{H}_{0}$ diterima sehingga dapat disimpulkan sampel berasal dari distribusi normal.

Penelitian diawali dengan pemberian soal pretest atau sebelum siswa mendapatkan perlakuan dengan model CIRC. Diakhir pembelajaran dilakukan postest atau siswa telah mendapatkan perlakuan pembelajaran model CIRC. Berdasarkan hasil pretest dan posttest didapatkan nilai hasil belajar seperti pada tabel berikut :

Tabel 1 Data hasil belajar Pretest dan

$$
\text { Posttest }
$$

\begin{tabular}{lcc}
\hline \multicolumn{1}{c}{ Keterangan } & Pretest & Posttest \\
\hline Nilai Tertinggi & 80 & 80 \\
Nilai Terendah & 33 & 37 \\
Rata-Rata & 57,33 & 70,22 \\
Siswa tuntas & 7 & 13
\end{tabular}

Kemudian dilakukan uji t-test yang diperoleh dari kegiatan pretes dan postes yang dilakukan untuk membuktikan apakah model CIRC efektif atau tidak terhadap hasil belajar membaca intensif siswa kelas III SDN Bogorame Rembang. Kriteria uji $t$-test adalah $t_{\text {hitung }} \geq \mathrm{t}_{\text {tabel }}$, maka $\mathrm{H}_{0}$ ditolak artinya model CIRC efektif terhadap hasil belajar membaca intensif siswa kelas III SDN Bogorame Rembang. 
Tabel 1. Hasil Uji t-tes

\begin{tabular}{lcc}
\hline \multicolumn{1}{c}{ Keterangan } & Pretes & Postes \\
\hline Jumlah & $860 \quad 1053$ \\
Keterangan & Jumlah \\
$\mathrm{Md}$ & 40 \\
$\sum \mathrm{X}^{2} \mathrm{~d}$ & 2666,6667 \\
$\mathrm{~N}=(\mathrm{N}-1)$ & $15-1=14$ \\
$\mathrm{t}_{\text {hitung }}$ & 4,49862 \\
$\mathrm{t}_{\text {tabel }}$ & 2.14479 \\
Keterangan & $\mathrm{H}_{0}$ ditolak
\end{tabular}

Dari tabel 4.5 dapat disimpulkan $t_{\text {hitung }}$ sebesar 4,49862 dan $t_{\text {tabel }}$ diperoleh dari $\mathrm{db}$ $=(\mathrm{N}-1)=15-1=14$ taraf signifikan 5\% $(0,05)$ sebesar 2.14479. Kriteria $t_{\text {hitung }} \geq t_{\text {tabel, }}$ 4,49862 $\geq 2.14479$ maka $\mathrm{H}_{0}$ ditolak dan $\mathrm{H}_{\mathrm{a}}$ diterima. Artinya rataan hasil belajar membaca intensif siswa sebelum dan sesudah perlakuan tidak sama/meningkat sehingga model CIRC terbukti efektif.

Berdasarkan penelitian menunjukkan bahwa penggunaan model CIRC efektif untuk meningkatkan hasil belajar membaca intensif siswa. Hal ini dibuktikan dengan adanya peningkatan nilai pretest dan posttest dan hasil uji t-test yang menunjukkan $t_{\text {hitung }}>t_{\text {tabel }}$, sehingga terbukti bahwa model CIRC efektif terhadap hasil belajar membaca intensif siswa.

\section{SIMPULAN}

Berdasarkan hasil penelitian dan pembahasan, maka dapat disimpulkan bahwa model CIRC efektif terhadap hasil belajar membaca intensif siswa kelas III SDN Bogorame Rembang. Hal tersebut ditunjukkan dengan hasil perhitungan ratarata nilai pretes < rata-rata nilai postes $\geq$ $\operatorname{KKM}(57,33<70,22 \geq 64)$. Selain itu berdasarkan hasil uji t-test diperoleh thitung sebesar 4.49862 dan $\mathrm{t}_{\text {tabel }}$ diperoleh dari $\mathrm{db}=$ $(\mathrm{N}-1)=15-1=14$ taraf signifikan 5\% $(0,05)$ sebesar 2.14479. Jadi thitung $4.49862 \geq \mathrm{t}_{\text {tabel }}$ 2.14479. Karena $t_{\text {hitung }} \geq t_{\text {tabel, }}$ maka $\mathrm{H}_{0}$ ditolak. Artinya rataan hasil belajar membaca intensif siswa sebelum dan sesudah perlakuan tidak sama/meningkat.

\section{DAFTAR PUSTAKA}

Dalman. 2017. Ketrampilan Membaca. Jakarta: Rajawali Pers.

Tarigan, Henry Guntur. 2008. Membaca Sebagai Suatu Ketrampilan Berbahasa. Bandung: Angkasa.

Ratumanan.2015. Inovasi Pembelajaran. Yogyakarta: Penerbit Ombak.

Ma'arif, Syamsul. 2012. Guru Profesional. Semarang: Need's Pers.

Huda, Miftahul. 2017. Model-model Pengajaran dan Pembelajaran. Yogyakarta: Pustaka Pelajar.

Huda, Miftahul. 2013. Cooperative Learning. Yogyakarta: Pustaka Pelajar.

Suprijono, Agus. 2017. Cooperative Learning. Yogyakarta: Pustaka Pelajar.

Thobroni.2017. Belajar dan Pembelajaran. Yogyakarta: Ar-ruzz Media.

Kosasih, Nandang dan Dede Sumarna. 2013. Pembelajaran Quantum dan Optimalisasi Kecerdasan. Bandung: Alfabeta, cv.

Subyantoro. 2013. Teori Pembelajaran Bahasa. Semarang: UNNES Press.

Rusman. 2017. Belajar dan Pembelajaran Berorientasi Standar Proses Pendidikan. Jakarta: Kencana.

Rahim, Farida. 2008. Pengajaran Membaca di Sekolah Dasar. Jakarta: Bumi Aksara.

Nurhadi. 2016. Teknik Membaca. Jakarta: Bumi Aksara.

Sutirman. 2013. Model-model Pembelajaran Inovatif. Yogyakarta: Graha Ilmu.

Slavin, Robert E. 2010. Cooperative Learning. Bandung: Nusa Media.

Ngalimun. 2017. Strategi Pendidikan. Yogyakarta: Parama Ilmu.

Sugiyono. 2016. Metode Penelitian Pendidikan. Bandung: Alfabeta, cv.

Arikunto, Suharsimi. 2013. Dasar-Dasar Evaluasi Pendidikan. Jakarta: Bumi Aksara. 
Kuswanda,P.A., dkk. 2014.Pengaruh Model Pembelajaran Kooperative Tipe CIRC Terhadap Hasil Belajar IPS Siswa Kelas V Di Desa Panarukan.Jurnal Mimbar PGSD Universitas Pendidikan Ganesha Jurusan PGSD (Vol: 2 No:1 Tahun 2014).

Utami, Citra Padma, dkk. 2014. Pengaruh Model Cooperative Integrated Reading and Composition terhadap Hasil Belajar IPA Siswa Kelas V. Jurnal Mimbar PGSD Universitas Pendidikan Ganesha Jurusan PGSD (Vol: 2 No:1 Tahun 2014). 